\title{
The Future Role of the Family Physician in the United States: A Rigorous Exercise in Definition
}

\author{
Robert L. Pbillips Jr, MD, MSPH \\ Stacy Brungardt ${ }^{2}$ \\ Sarab E. Lesko, MD, MPH \\ Nathan Kittle ${ }^{3}$ \\ Jason E. Marker, $M D^{4}$ \\ Michael L. Tuggy, $M D^{5}$ \\ Michael L. LeFevre, $M D^{2}$ \\ Jeffrey M. Borkan, $M D, P b D^{6}$ \\ Frank V. DeGruy, $M D^{7}$ \\ Glenn A. Loomis, $M D^{8}$ \\ Nathan Krug, MD \\ 'The American Board of Family Medicine, \\ Lexington, Kentucky \\ ${ }^{2}$ Society of Teachers of Family Medicine, \\ Leawood, Kansas \\ ${ }^{3}$ Swedish Family Medicine Residency Pro- \\ gram - Cherry Hill, Seattle, Washington \\ ${ }^{4}$ American Academy of Family Physicians

\begin{abstract}
As the US health care delivery system undergoes rapid transformation, there is an urgent need to define a comprehensive, evidence-based role for the family physician. A Role Definition Group made up of members of seven family medicine organizations developed a statement defining the family physician's role in meeting the needs of individuals, the health care system, and the country. The Role Definition Group surveyed more than 50 years of foundational manuscripts including published works from the Future of Family Medicine project and Keystone III conference, external reviews, and a recent Accreditation Council on Graduate Medical Education Family Medicine Milestones definition. They developed candidate definitions and a "foil" definition of what family medicine could become without change. The following definition was selected: "Family physicians are personal doctors for people of all ages and health conditions. They are a reliable first contact for health concerns and directly address most health care needs. Through enduring partnerships, family physicians help patients prevent, understand, and manage illness, navigate the health system and set health goals. Family physicians and their staff adapt their care to the unique needs of their population, and use best science to prioritize services most likely to benefit health. They are ideal leaders of health care systems and partners for public health." This definition will guide the second Future of Family Medicine project and provide direction as family physicians, academicians, clinical networks, and policy-makers negotiate roles in the evolving health system.
\end{abstract} \\ patients and communities. They use data to monitor and manage their patient
} Foundation, Leawood, Kansas

${ }^{5}$ Association of Family Medicine Residency Directors, Leawood, Kansas

${ }^{6}$ Association of Departments of Family Medicine, Leawood, Kansas

${ }^{7}$ North American Primary Care Research Group, Leawood, Kansas

${ }^{8}$ American Academy of Family Physicians, Leawood, Kansas

Conflicts of interest: authors report none.

\section{CORRESPONDING AUTHOR}

Robert L. Phillips Jr, MD, MSPH ${ }^{1}$

The American Board of Family Medicine 1133 Connecticut Ave NW, Suite 1100 Washington, DC 20036

bphillips@theabfm.org

Ann Fam Med 2014;250-255. doi: 10.1370/afm.1651.

\section{INTRODUCTION}

A $t$ the turn of the century, family medicine leaders organized the Keystone III Conference to "examine the soul of the discipline of family medicine, and to take stock of the present and grapple with the future of family practice."1 This conference inspired the major family medicine organizations to organize the Future of Family Medicine Project (FFM) charged to "[d]evelop a strategy to transform and renew the specialty of family practice to meet the needs of people and society in a changing environment." Many successes were born out of FFM, but the decade that followed saw erosion of primary care training, a decline in student and resident interest, and a widening of the physician income gap. Currently, while family medicine and primary care are fighting pressures from insurers and purchasers, they are enjoying a renaissance thanks to considerable forces for health reform, including the Affordable Care Act. The major family medicine organizations have launched the FFM 2.0 Project to offer leadership in how family medicine responds to these opportunities.

Despite at least 1 attempt to characterize the family physician's role a decade ago, ${ }^{3}$ family medicine's lack of a role definition hampered its ability to prioritize and strategize its advocacy:

The role of family practice in US culture is now less clear than the potential role envisioned for it in 1969. Its multiple and not always well-defined roles in medicine may make it difficult to establish a clear identity for the specialty in the future. If 
it is to be successful, family practice must develop allies and work aggressively to establish its role in primary care. ${ }^{2}$

This concern led to the formation of a Role Definition Group composed of representatives from each of the family medicine organizations and representing a variety of perspectives on family medicine (see "Author professional characteristics" at the end of the article). The specific charge for the group stated, "There is an urgent need to establish a widely endorsed, proper role of the family doctor in the United States' rapidly transforming health care delivery system. Clarity and consensus about the role of family doctors going forward is foundational to communication, education, research, and advocacy strategies." The group was asked to develop a "laminated card' statement of 100 words or less that states the role that the US public needs to have filled by family doctors in order for individuals to have longer, better lives and the country to achieve the triple aim."

Members of the Role Definition Group reviewed peer-reviewed and gray literature from the past 60 years looking for role definitions or elements thought to be critical to the role of the generalist or family physician. Three sources will serve to typify the kinds of publications we identified. In 1968, Bryan described the role of family physicians as including care and management of whole patients who were evaluated in the context of their families, homes, jobs, and personal histories. The family physician, Bryan said, had the task of "synthesizing where his fellows particularize," accepted responsibility for the patient, and used specialists rather than surrendering to them. ${ }^{4}$ Bryan also suggested that the family physician would "find a new and broader role as community functionary."

Even earlier, in 1961, Fox said of "personal doctoring,"

A person in difficulties wants in the first place the help of another person on whom he can rely as a friend-someone with knowledge of what is feasible but also with good judgment on what is desirable in the particular circumstances, and understanding of what the circumstances are. The more complex medicine becomes, the stronger are the reasons why everyone should have a personal doctor who will take continuous responsibility for him, and knowing how he lives, will keep things in proportion-protecting him, if need be, from a zealous specialist. ${ }^{5}$

Fox felt that the defining characteristic of the family physician is "looking after people as people and not as problems." Bryan and Fox both emphasized that the generalist role was complex, protective, and based on on a personal relationship and that it required knowledge of the whole patient.

These progenitors of family medicine recognized the role of a care team in enhancing the breadth of care needed in family medicine, but also called for a balance of delegation and personal care to preserve relationships. Bryan described the family physician as "a director, rather than a doer-a manager rather than a technician," "relat[ing] parts to whole, the machinery to the purpose, the special talent to the basic task," and as someone who "delegates every conceivable operational task to his aides...the so-called 'health team."' According to him, the family physician "will acknowledge the need to admit paramedical people of many kinds...into a defined partnership, and...learn how to grant them

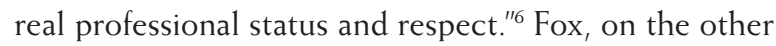
hand, while accepting that the personal doctor of the future will be the leader of a team, cautioned against carrying the delegation too far: "Organization can be a menace to the personal care we are supposed to be organizing." He also emphasized that "[t]o be a personal doctor one must remain a real doctor, and not turn into the manager of a practice." Stephens, a father of US family medicine, extended the traditional definition of comprehensive care to include personal medicine, behavioral orientation, and family orientation. ${ }^{7}$

These and many other foundational documents furnished the background for the task of the Role Definition Group. We often had difficulty trying to tease role from characteristics and scope and trying to derive a definition for the discipline from the specific roles of its practitioners. Our intent was to define the role family physicians should be prepared to fill while recognizing that practice settings and community need would naturally modify the roles of individual family physicians to some extent.

\section{Brief Explanation of Our Process}

The Role Definition Group operated for 3 months to accomplish this task, which was broken down into the following steps:

1. Literature review of family medicine and primary care definitions, including Keystone III and FFM monographs and peer-review publications

2. Group discussion of task and background literature

3. Individual composition of sample definitions and "foil" definitions-definitions of the role family medicine risked adopting without redirection

4. Group discussion of deidentified definitions

5. Second round of individual composition of refined definitions and foil definitions

6. Input from external experts involved in Keystone III and FFM

7. Group discussion including deconstruction of 2 definitions into component concepts and review of distilled role definition from a parallel effort by the Accreditation Council on Graduate Medical Education Family Medicine Milestones report 
8. Individual ratings of component concepts on a 1 to 5 scale with compilation of results

9. Individual review and group discussion of results from rating

10. Third round of definition composition that took the component concept ratings into account

11. Group discussion and refinement

12. Final comments

13. Compilation of the FFM 2.0 Role Definition Group's final definition along with those written by the ACGME Family Medicine Milestone committee and by Rosemary Stevens, $\mathrm{MD}^{8}$

These definitions and a foil definition were then presented, with background, to a meeting of the elected and staff leadership of each of the 6 academic family medicine organizations gathered for the biannual Family Medicine Working Party, all of whom voted to rank the definitions by order of preference. The FFM 2.0 Role Definition Group's definition was overwhelmingly preferred. Outside reviewers and Working Party participants felt that the foil definition was already a starkly accurate description of many family physicians' current roles. The selected definitions are shown in Table 1. Two optional definitions and a table showing the group's scoring of individual elements are included in the Supplementary Appendix.

\section{Exploration of Definition Elements}

The following is an 'unpacking' of the components of the selected definition. We provide further citations of ideas and evidence that supported these definition components, as well as explanations of meaning, reasoning for our choices, and, often, language we considered as alternatives.

\section{Family Physicians are Personal Doctors for People of All Ages and Health Conditions}

This reflects the earliest principles of primary care and is family medicine's legacy from general practice. ${ }^{9,10}$ It reflects the importance of relationships and of care that does not discriminate by organ system, condition or setting. ${ }^{11}$ The combination of trusted relationships and whole-person care is generally unique to family medicine and is believed to be central to findings of lower costs and improved outcomes associated with family medicine vs other care. ${ }^{12-14}$ The combination adds complexity to decision making and care management in that it integrates the patient's val- ues and conditions to guide and prioritize care and to protect patients from over-treatment. It also speaks to a broad scope of practice that can include obstetrical care, office-based procedures, and caring for people in emergency rooms and in hospitals.

\section{Family Physicians Are a Reliable First Contact for Health Concerns and Directly Address Most Health Care Needs}

This concept is also a basic primary care tenet, embraced since the beginning of family medicine and before. ${ }^{9,15,16}$ It is a reminder that family medicine is a primary care discipline, heir to general practice, and that the role of the family physician will necessarily overlap with those of other primary care providers. First contact means that care is sought of the family physician without referral, and is often the only patient contact. ${ }^{17}$ This concept also speaks to comprehensiveness and the capacity to handle most of the needs brought to them. ${ }^{11,18}$

\section{Through Enduring Partnerships, Family Physicians} Help Patients Prevent, Understand, and Manage Illness, Navigate the Health System and Set Health Goals

Continuity is important to a majority of patients, particularly those from vulnerable groups, and most patients prefer to see their own physicians. ${ }^{19,20}$ It is associated with greater satisfaction, better compliance, and lower hospitalization and emergency room use. ${ }^{21-24}$ The Millis Commission report preferred the term longitudinality to continuity, and Barbara Starfield once wrote, "Continuity is a mechanism to achieve knowledge; longitudinality is the mechanism for achieving understanding. ${ }^{\prime 25}$ She described longitudinality as being personfocused and not disease focused. ${ }^{26}$ The workgroup felt that "enduring partnerships" captured the intent of both continuity and longitudinality, offering a deeper sense that it is person-centered, and to convey that it

\section{Table 1. The Selected Definitions}

\section{Selected Role Definition}

Family physicians are personal doctors for people of all ages and health conditions. They are a reliable first contact for health concerns and directly address most health care needs. Through enduring partnerships, family physicians help patients prevent, understand, and manage illness, navigate the health system and set health goals. Family physicians and their staff adapt their care to the unique needs of their patients and communities. They use data to monitor and manage their patient population, and use best science to prioritize services most likely to benefit health. They are ideal leaders of health care systems and partners for public health.

\section{Foil Definition}

The role of the US family physician is to provide episodic outpatient care in 15-minute blocks with coincidental continuity and a reducing scope of care. The family physician surrenders care coordination to care management functions divorced from practices, and works in small, illdefined teams whose members have little training and few in-depth relationships with the physician and patients. The family physician serves as the agent of a larger system whose role is to feed patients to subspecialty services and hospital beds. The family physician is not responsible for patient panel management, community health, or collaboration with public health. 
is not just a temporal partnership but one that extends across settings. Partnership also puts the patient on an equal footing in a way that the commonly used "relationship" does not. By setting it first in the sentence, the workgroup hoped to convey that the partnership is critical to all the functions that follow. The first three of these functions are about illness-preventing, educating about, and ultimately dealing with illness. The fourth function is intended to capture how family physicians help guide patients through the health system, getting appropriate care and avoiding unnecessary or harmful treatment. This can be as their physician, their advocate, or both. Finally, this definition component speaks to the function of helping patients set and achieve goals, which mature and change over time, including decisions about the care they want to receive or avoid at the end of life.

Family Physicians and Their Staff Adapt Their Care to the Unique Needs of Their Patients and Communities

This element describes a need for flexibility-that the care and the people who provide it will shift to meet the needs particular to their patients and community. ${ }^{27}$ It is also meant to convey the concept of teamwork-that robust primary care is beyond the capacity of anyone to do alone and requires multiple skill sets and people to meet the needs of their patients. The phrase "patients and communities" includes families, which is unique among primary care providers. ${ }^{11,16}$ Family physicians' role in community, although vital, is not well described for the specialty, even though there are many examples of individual family physicians who have taken larger roles in their communities. ${ }^{28}$ It is also a challenge recently remade by the Institute of Medicine (IOM). ${ }^{29}$

\section{Family Physicians Use Data to Monitor and Manage} Their Patient Population, and Use Best Science to Prioritize Services Most Likely to Benefit Health This element acknowledges that the value of care we provide is increasingly dependent upon expertise in understanding and managing information. The explosion of medical knowledge requires family physicians to apply increasingly sophisticated filters to bring the best available science to the decisions we make with our patients. Similarly, electronic health records are capturing heaps of data that must be effectively managed and distilled into information to guide personal and population care. More than a decade ago, the National Committee on Vital and Health Statistics published Information for Health: A Strategy for Building the National Health Information Infrastructure. ${ }^{30}$ This report expounded a vision for an information infrastructure that could share "information and knowledge appro- priately so it is available to people when they need it to make the best possible health decisions." The report went on to say that this infrastructure needed to serve individuals and communities. With maintenance of certification, payment incentives and penalties, and increasing focus on organizational accountability, the pressure to monitor and measure patient outcomes is increasing. The IOM report on integration of primary care and public health also envisions a day when family physicians will be able to connect their data to public health and population data to better understand how to help our patients and our communities. ${ }^{29}$

\section{Family Physicians Are Ideal Leaders of Health Care} Systems and Partners for Public Health

As health care systems are increasingly paid to manage populations accountably, they will need leaders who know those populations, often serving as their only point of contact with the system. More care will migrate out of inpatient and subspecialty care, and primary care will have greater capacity for comprehensive care. True population health accountability will also require greater partnership with public health and social services. ${ }^{29}$ These existing and needed relationships make family physicians ideal midwives for expectant health care systems. We have never had as many family physician deans and academic health system vice presidents as we have right now. This leadership coterie developed in less than a decade and portends even more family medicine leadership to come. We need to prepare the next generation of family medicine trainees for these roles, and as partners to public health.

\section{DISCUSSION}

Stevens observed that, "In the absence of role definition through clinical service structures in the United States...family practice had no choice but to relate to other specialties according to the latter's ground rules." ${ }^{2}$ Stephens recognized that the family practice movement of the previous decade had succeeded, "because we were identified with reforms that are more pervasive and powerful than ourselves." ${ }^{111}$ At this moment, family medicine is being swept along by currents of health care reform, including the Affordable Care Act, that are more powerful than the discipline. We must take advantage of this tide to promote a role for family physicians that is not subservient to others' ground rules. A few examples of what is pulling this tide follow:

\section{Patient-Centered Medical Home}

The Patient-centered Medical Home (PCMH) is a primary care practice transformation that grew out of the Chronic Care Model and observations of high- 
performing practices. ${ }^{32-34}$ With its move toward more robust teams, patient-centered and whole person focus, empowerment through health information technology, and a focus on quality and safety, the PCMH offers a chance to clarify the role of family physicians.

\section{Accountable Care Organizations}

The Medicare Payment Advisory Commission (MedPAC) states that an Accountable Care Organization (ACO) is "a set of physicians and hospitals that accept joint responsibility for the quality of care and the cost of care received by the ACO's panel of patients." ${ }^{135}$ MedPAC regards medical homes as building blocks of effective ACOs, but ACOs do not all offer family physicians the same role. Family physicians are also torn about their role in this larger context, and anxious about how and when to embrace changes it will require. ${ }^{36}$

\section{The Triple Aim}

We began with the Triple Aim for health care as the frame for our charge. It has these goals: (1) improving the experience of care $_{i}(2)$ improving the health of populations; and, (3) reducing per capita costs of health care. ${ }^{37}$ The Triple Aim was embraced formally by the Centers for Medicare and Medicaid Services as an explicit payment and policy objective. ${ }^{38}$ It is a potent force for change that is likely to require more robust, broad-scope primary care, and it is aligning with the $\mathrm{PCMH}$ and the ACO in the form of demonstration projects and quality measures.

These are just 3 of the environmental pressures for health system change and primary care transformation. With role clarification, there is potential for family medicine to make the most of this wave of change; without it there is greater risk that others will dictate roles. For example, there is a growing tendency to regard the family physician as a manager overseeing teams with large patient panels, neglecting the value of relationships in favor of efficiency. ${ }^{39,40}$

\section{CONCLUSION}

The Role Definition Group feels that the proposed role definition and its foil offer 2 visions for how family medicine could respond to the strong shifts happening in health care today. Family medicine has spent the last decade or more reducing its scope of practice despite a clear call by the FFM for a broader basket of services and evidence that comprehensiveness is one of the value-added features of primary care. ${ }^{41,42}$ It will not be easy for the specialty to live up to this aspirational definition. It may take a decade-or even a generation-to get there. The definition offers a goal for strategies to win over the next generation of students, reorient training models, and reconfigure graduate medical education payments as primary care production of training programs has fallen to an all-time low. ${ }^{43}$ Payment and care-model experiments now underway are bringing with them important new investments in outpatient training, new experiments with family medicine training design, and a new focus in preparing faculty for these new models of care. ${ }^{44}$

Clarifying the family physician's role is critical to the discipline's future success and likely even to its future existence. Embracing a new definition and, perhaps more important, rejecting the foil, are important steps as family medicine negotiates with government, payers, health systems, patients and communities and builds the Future of Family Medicine 2.0.

To read or post commentaries in response to this article, see it online at http://www.annfammed.org/content/12/3/250.

Key words: family physicians; family practice; family medicine; professional practice; professional role

Submitted August 5, 2013; submitted, revised, January 22, 2014; accepted March 5, 2014.

Funding support: Supported by the listed family medicine organizations with administrative support by the Society of Teachers of Family Medicine.

Prior presentation: This work was previously presented to the Family Medicine Working Party in January, 2013, and to the Pisacano Leadership Foundation in April, 2013.

Author professional characteristics: Perspectives of the listed group members may be shaped in part by the following professional characteristics :

Chair of a family medicine department (J.B., F.D.)

CEO of a physician-owned, multi-specialty group (G.L.)

Former practice-based research network director (J.B.)

Rural private practice (J.M.)

International practice or practice innovation research (J.B., R.P.)

Currently do obstetrics and inpatient care (M.T., M.L., J.M.)

Residency program director (M.T.)

Former military service (M.T., G.L.)

Community Health Center physician (S.L.)

Evidence-based medicine leader (M.L.)

Primary care mental health research and development (F.D.)

Practice innovation evaluation and research (R.P., J.B.)

Health policy advising (R.P., J.B., F.D., M.L.)

In training (N.K. and N.K.)

Supplementary materials: Available at http://www.AnnFamMed. org/content/12/3/250/suppl/DC1

\section{References}

1. Green LA, Graham R, Stephens GG, Frey JJ, eds. Special Dedication Issue: The Keystone Papers: Formal Discussion Papers from Keystone III. Fam Med. 2001;(33)4:230-324. http://www.stfm.org/ FamilyMedicine/Vol33Issue4. Accessed Aug 2, 2013. 
2. Stevens RA. The Americanization of family medicine: contradictions, challenges, and change, 1969-2000. Fam Med. 2001;33(4):232-243.

3. Phillips WR, Haynes DG. The domain of family practice: scope, role, and function. Fam Med. 2001;33(4):273-277.

4. Bryan JE. The family physician-a functional specialist. In: The Role of the Family Physician in America's Developing Medical Care Program: A Report and Commentary. St. Louis, MO: Warren H. Green, Inc; 1968.

5. Fox TF. The personal doctor and his relation to the hospital. Observations and reflections on some American experiments in general practice by groups. Lancet. 1960;1(7127):743-760.

6. Bryan JE. Summing Up. In: The Role of the Family Physician in America's Developing Medical Care Program: A Report and Commentary. St. Louis, MO: Warren H. Green, Inc; 1968.

7. Stephens GG. The best ideal in family practice. J Am Board Fam Pract. 1991;4(4):223-228.

8. Accreditation Council for Graduate Medical Education, American Board of Family Medicine. The Family Medicine Milestones Project. Chicago, IL: ACGME; 2013.

9. Institute of Medicine. Defining Primary Care: An Interim Report. Washington, DC: National Academy Press; 1994.

10. DeVoe JE, Nordin T, Kelly K, et al. Having and being a personal physician: vision of the Pisacano Scholars. J Am Board Fam Med. 2011;24(4):463-468.

11. Millis JS. The Graduate Education of Physicians. Report of the Citizens' Commission on Graduate Medical Education. Chicago, IL: American Medical Association; 1966.

12. Starfield B, Shi L, Macinko J. Contribution of primary care to health systems and health. Milbank Q. 2005;83(3):457-502.

13. Phillips RL, Dodoo MS, Green LA, et al. Usual source of care: an important source of variation in health care spending. Health Aff (Millwood). 2009;28(2):567-577.

14. Stange KC, Ferrer RL. The paradox of primary care. Ann Fam Med. 2009;7(4):293-299.

15. World Health Organization. Declaration of Alma-Ata. Paper presented at: International Conference on Primary Health Care 1978; Alma-Ata, USSR.

16. Alpert JJ, Charney E. The Education of Physicians for Primary Care. Rockville, MD: Bureau of Health Services Research, Health Resources and Services Administration, Department of Health, Education, and Welfare; 1973.

17. White KL, Williams TF, Greenberg BG. The ecology of medical care. N Engl J Med. 1961;265(18):885-892.

18. Ferrer RL, Hambidge SJ, Maly RC. The essential role of generalists in health care systems. Ann Intern Med. 2005;142(8):691-699.

19. Saultz JW, Albedaiwi W. Interpersonal continuity of care and patient satisfaction: a critical review. Ann Fam Med. 2004;2(5):445-451.

20. Nutting PA, Goodwin MA, Flocke SA, Zyzanski SJ, Stange KC. Continuity of primary care: to whom does it matter and when? Ann Fam Med. 2003;1(3):149-155.

21. Freeman $G$, Hjortdahl p. What future for continuity of care in general practice? BMJ. 1997-06-28 08:00:00 1997;314(7098):1870.

22. Saultz JW, Lochner J. Interpersonal continuity of care and care outcomes: a critical review. Ann Fam Med. 2005;3(2):159-166.

23. Gill JM, Mainous AG III. The role of provider continuity in preventing hospitalizations. Arch Fam Med. 1998;7(4):352-357.

24. De Maeseneer JM, De Prins L, Gosset C, Heyerick J. Provider continuity in family medicine: does it make a difference for total health care costs? Ann Fam Med. 2003;1(3):144-148.
25. Starfield B. Continuity and longitudinality [eletter]. Ann Fam Med. 2003. http://www.annfammed.org/cgi/eletters/1/3/144\#82. Accessed Aug 1, 2013.

26. Starfield B. Primary Care: Balancing Health Needs, Services, and Technology. New York, NY: Oxford University Press; 1998.

27. Group TF. Communities of solution: The Folsom Report revisited. Ann Fam Med. 2012;10(3):250-260.

28. Farley ESJ Jr, Boisseau V, Froom J. An integrated medical record and data system for primary care. Part 5: Implications of filing family folders by area of residence. J Fam Pract. 1977;5(3):427-432.

29. Institute of Medicine. Primary Care and Public Health: Exploring Integration to Improve Population Health. Washington, DC: The National Academies Press; 2012.

30. National Committee on Vital and Health Statistics. Information for Health: A Strategy for Building the National Health Information Infrastructure. Washington, DC: Centers for Disease Control and Prevention, US Department of Health and Human Services; 2001.

31. Stephens GG. Family medicine as counterculture. 1979. Fam Med. 1998;30(9):629-636.

32. Rittenhouse DR, Shortell SM. The patient-centered medical home: will it stand the test of health reform? JAMA. 2009;301(19):2038-2040.

33. Stange $K$, Nutting $P$, Miller $W$, et al. Defining and measuring the patient-centered medical home. J Gen Intern Med. 2010;25(6):601-612.

34. Rosenthal TC. The medical home: growing evidence to support a new approach to primary care. J Am Board Fam Med. 2008;21(5): 427-440.

35. Medicare Payment Advisory Commission. Accountable Care Organizations. Report to the Congress: Improving Incentives in the Medicare Program. Washington, DC: MEDPAC; 2009.

36. Goldberg DG, Mick SS, Kuzel AJ, Feng LB, Love LE. Why do some primary care practices engage in practice improvement efforts whereas others do not? Health Serv Res. 2013:48(2 Pt 1)(2pt1):398-416.

37. Berwick DM, Nolan TW, Whittington J. The triple aim: care, health, and cost. Health Aff (Millwood). 2008;27(3):759-769.

38. Fleming C. Berwick brings the 'Triple Aim' to CMS. Health Affairs Blog. 2010. http://healthaffairs.org/blog/2010/09/14/berwickbrings-the-triple-aim-to-cms/.

39. Green LV, Savin S, Lu Y. Primary care physician shortages could be eliminated through use of teams, nonphysicians, and electronic communication. Health Aff (Millwood). 2013;32(1):11-19.

40. Chen PG, Mehrotra A, Auerbach DI. Do we really need more physicians? Responses to predicted primary care physician shortages. Med Care. 2014;52(2):95-96.

41. Bazemore AW, Petterson S, Johnson N, et al. What services do family physicians provide in a time of primary care transition? J Am Board Fam Med. 2011;24(6):635-636.

42. Martin JC, Avant RF, Bowman MA, et al; Future of Family Medicine Project Leadership Committee. The future of family medicine: a collaborative project of the family medicine community. Ann Fam Med. 2004;2(Suppl 1):S3-S32.

43. Chen C, Petterson SM, Phillips RL, Mullan F, Bazemore AW, O'Donnel SD. Towards graduate medical education accountability: measuring the outcomes of GME institutions. Acad Med. 2013;88(9):1267-1280.

44. Chen C, Chen F, Mullan F. Teaching health centers: a new paradigm in graduate medical education. Acad Med. 2012;87(12):1752-1756. 